\title{
Estimation of Different Categories of Healthcare Waste Generated at Two Different Hospital Categories in Four Hospitals in Dar es Salaam City
}

\author{
Honest Anicetus $^{1}{ }^{*}$ Josephat Saria ${ }^{2}$, Hussein Mohamed ${ }^{3}$ \\ ${ }^{1}$ Ministry of Health, Community Development, Gender, Elderly and Children, Dodoma, Tanzania \\ ${ }^{2}$ Open University of Tanzania, Department of Environmental Studies, Dar es Salaam, Tanzania \\ ${ }^{3}$ Muhimbili University of Health and Allied Sciences, Dar es Salaam, Tanzania \\ Email: ^hanicetus@gmail.com
}

How to cite this paper: Anicetus, H., Saria, J. and Mohamed, H. (2020) Estimation of Different Categories of Healthcare Waste Generated at Two Different Hospital Categories in Four Hospitals in Dar es Salaam City. Journal of Environmental Protection, 11, 872-888.

https://doi.org/10.4236/jep.2020.1110055

Received: September 3, 2020

Accepted: October 18, 2020

Published: October 21, 2020

Copyright $\odot 2020$ by author(s) and Scientific Research Publishing Inc. This work is licensed under the Creative Commons Attribution International License (CC BY 4.0).

http://creativecommons.org/licenses/by/4.0/

(c) (i) Open Access

\begin{abstract}
This study aims to estimate the quantity of healthcare waste categorically generated in four different healthcare in Dar es Salaam city namely, Muhimbili National Hospital, Mwananyamala Regional Referral Hospital, Temeke Regional Referral Hospital and Ilala Regional Referral Hospital to evaluate the quantities of medical waste generated based on their level and capacity. Waste was collected in different categories of non-infectious, sharps, infectious, infectious plastics, and pathological waste which were measured daily for fourteen (14) consecutive days in all hospitals by using a weighting scale and observational checklist to document related waste management information and the assessment of the healthcare waste generation in each hospital. The average general healthcare waste generation rate per healthcare ranges from 298.9 $\mathrm{kg} /$ day to $1554.4 \mathrm{~kg} /$ day. The high fluctuation in general medical waste was established to be attributed to specialization difference between one hospital to the other, and the large number of in-patients and out patients between hospitals. The overall average sharps waste generation rate was established to range from $8.5 \pm 2.7-13.9 \pm 1.8 \mathrm{~kg} /$ day. Higher values of sharps waste generated observed at Muhimbili hospital are due to emergency cases referred to from other hospitals located within the city and from the surrounding districts and other regions of the country. The results from this study, raise alarm to hospital administrators, and other health stakeholders working in related fields to give special attention and priority in setting a related share in their budgets for proper management of medical waste in their health facilities.
\end{abstract}




\section{Keywords}

Healthcare, Dar es Salaam, Infectious Waste, Environmental Hazards, Medical Waste, Hospital Solid Waste

\section{Introduction}

There are extraordinary challenges for the healthcare systems and local governments in Africa involved in the response to the outbreak of deadly diseases like coronavirus disease 2019 (COVID-19) or Ebola and many of those challenges will persist long after the outbreak has passed [1]. The provision of sanitation services and handling of waste is essential for protecting human health during all infectious disease outbreaks, including COVID-19 [2]. One such challenge was the safe disposal of potentially infected healthcare waste especially in the overcrowded urban communities where many of the cases occurred [3].

Ensuring evidenced-based and consistently applied waste management practices in communities, homes, schools, marketplaces and healthcare facilities will help prevent human-to-human transmission of, the virus that causes COVID-19 [2]. The safe segregation and disposal of waste material that could harbor infected diseases is particularly challenging when that waste has been produced beyond any formal health-care setting [4].

Healthcare waste is classified as any possibly contaminated byproduct of medical research, treatment, or other healthcare activity [5]. Healthcare wastes can broadly be categorized into infectious waste and non-infectious waste. Management of healthcare waste is very important due to its infectious and hazardous nature that can cause risks on environment and public health [4]. Other wastes generated in healthcare are non-hazardous material which includes medication boxes, the packaging materials for medical items and food, office appliances and remains of foodstuff [6].

Awareness of risks associated with healthcare waste and its contemporary management systems has gained attention all over the world in various events, local and international meetings and summits. However, the pace for proper healthcare waste management has been very slow due to the substantial disease burdens associated with poor practices, including exposure to infectious agents and toxic substances [7]. Despite the magnitude of the problem, practices, capacities and policies in many countries in dealing with healthcare waste disposal, especially in Sub-Saharan countries, are inadequate and require to be strengthened.

The healthcare waste management is not merely the responsibility of the hospital administration but it is the duty of every department and every healthcare providing personnel in the healthcare [8]. This is the process which begins from the generation point where medical waste has to be properly collected and segregation which means separating different wastes into different color-coded 
bins with liners or sharps containers at locations where they are generated and it is always the first and the most important activity in HCWM [9].

Study conducted earlier, indicated that the major concern due to poor segregation involved injuries, the transmission of infections, environmental pollution, fire hazards, and public nuisances (offensive smells, unsightly debris, etc.) are the major risks and hazards of poorly managed the HCW [10]. Each year there are about 8 to 16 million new cases of Hepatitis B virus (HBV) about 80,000 160,000 cases of HIV and 2.3 - 4.7 million cases of Hepatitis C virus (HCV) due to unsafe injections disposal and mostly due to very poor waste management systems [11]. Hence, management of healthcare wastes requires special attention and needs to be assigned high priority [8]. According to World Health Organization [12], it has been estimated that during outbreak of Ebola, in a day patient in a healthcare center produced up to 300 litres of liquid waste and excreta. Every liter needs to be properly disposed because it could have been contaminated with Ebola so as to minimize the risks of transmission [13].

Healthcare center generates about $85 \%$ of general waste which is non-hazardous waste comparable to domestic waste, while about $15 \%$ is considered hazardous waste that may be infectious, chemical like drugs or radioactive materials [14]. These hazardous materials from healthcare units include radioactive substances, biohazardous waste, pharmaceutical wastes, chemicals, pathological wastes, and genotoxic wastes, which can cause a variety of adverse effects on human beings and the environment [15].

Healthcare waste generation depends on numerous factors (Figure 1) such as type of healthcare facilities (HCF) hospital specialization, available waste segregation mechanism, and seasonal variation, the number of hospital beds and out patients treated on a daily basis [16].

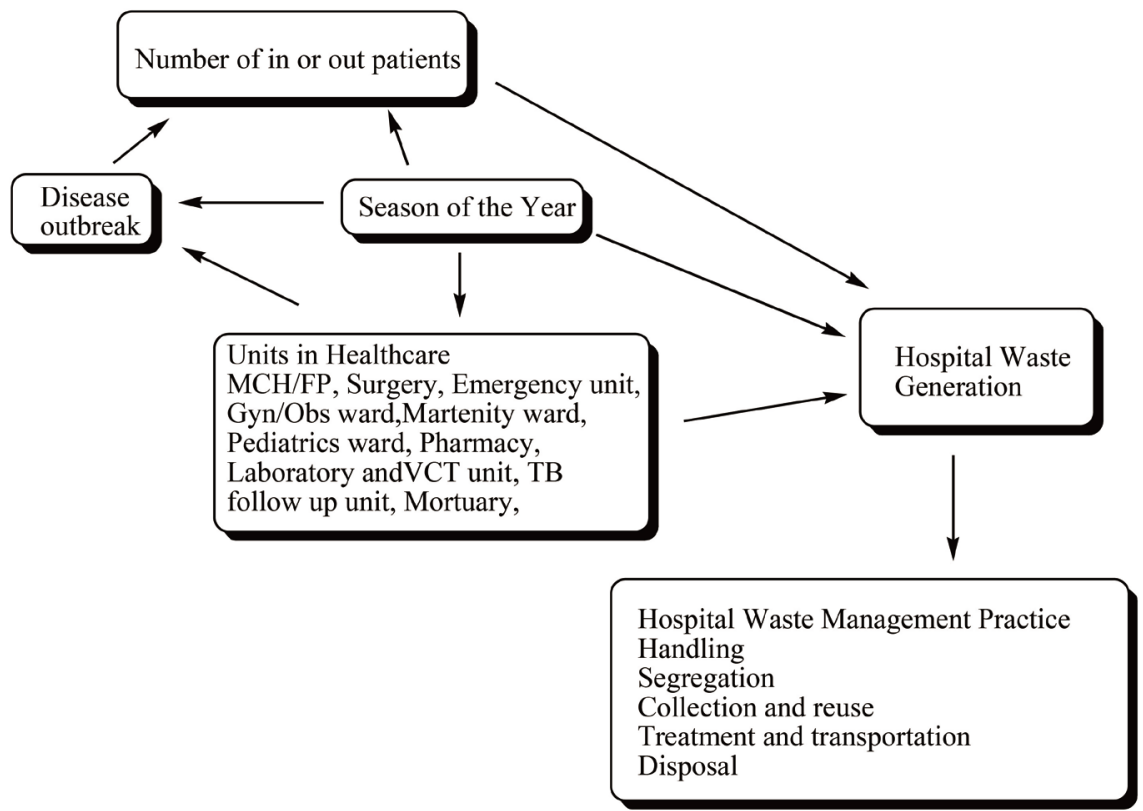

Figure 1. Factors that determine healthcare waste generation rate in healthcare setting. 
In developing countries there is a serious lack of reliable information on factors such as waste generation and waste characteristics, making it very difficult to identify appropriate and sustainable management solutions [17]. Most of Sub-Saharan countries lack national legislation and even simple segregation and treatment techniques [17]. Unfortunately, waste generation and resource consumption have greatly increased in healthcare, along with the rising production of hazardous byproducts, including hazardous chemicals like heavy metals, dioxins and furans [18].

The WHO has recommended technical guidelines as the basis for a national program of improvement of HCWM, together with a realistic legal framework, including designation of responsible authorities and mechanisms for coordination [19]. In this regard, Tanzania has developed national strategic plan in 2018 which can be implemented in all regional states of the country [20].

South Africa has shown very good action of dealing with healthcare waste. The waste minimization and reuse were accorded a priority consideration on solid waste management [21]. This shows that the country regarded the reduction from source as a very important step in the management of any type of solid waste. The Department of Environmental Affairs (DEA) of South Africa has been on the forefront of drafting waste (including HCRW) management guidelines as well as monitoring and conducting relevant studies on the subject nationwide [22].

Thus, to minimize the risks associated with improper management of healthcare wastes in Tanzania, it is imperative to understand the magnitude of waste generation categorically in order to facilitate planning, budgeting and develop evidence-based intervention strategy. Of current the data related with the generation rate of healthcare waste in the healthcare setting in Tanzania as it is the situation for most of East African countries and existing management. Therefore, the objective of this study is to calculate the average generation of healthcare waste in different categories per different hospital categories in Dar es Salaam city.

This study will facilitate benchmarking among hospitals by allowing them to compare their generation rates against other hospitals, which will help them to identify possibilities of improving the efficiency of their waste management system and predict their waste management expenses.

\section{Methodology}

Study Area, Study Design and Period: A cross-sectional study was conducted to assess healthcare waste generation rate and its management system of hospitals in Dar es Salaam City. The city with a population growth rate of about $8 \%$ per year is one of the fastest growing cities in Sub-Saharan Africa with a population of 6,701,650 [23]. The assessment of the amount and categories of healthcare waste was done in four healthcare facilities namely: Muhimbili National Hospital, Mwananyamala Regional Referral Hospital, Temeke Regional Referral Hospital and Ilala regional referral hospital. 
Observational checklist and weighing scale were used to assess the healthcare waste management system and its generation rate in each hospital. A walk-through inspection in all hospitals was done by the investigator in order to identify what type of waste was generated in relation to the nature of healthcare services in a healthcare setting. Waste was collected and measured daily and weighed for fourteen (14) consecutive days in all Hospitals (Figure 2). All categories of waste at the point of waste generation were collected using color coded bin liners for easy carrying and weighing too. Beside that waste was collected in a color coded standard waste bins.

Data Collection Tools and Procedures: Observational checklist and key informant interview were used to assess the management system. To determine the magnitude of waste generated the WHO guideline was followed [14]. Each pilot $\mathrm{HCF}$ was provided with $25 \mathrm{Kg}$ storage container with appropriate bin liners. The number of containers provided for each HCF depended on the number of functional units. Provision of containers was important for segregation purposes. All containers were well labeled as per guidelines. Field investigators placed designated bin-liners in each HCW generation unit at the start of a shift and collected the liners at the end of the shift, replacing it with a new one to continue the exercise. Waste generated were segregated and stored in the appropriate color coded containers with appropriate polyethylene bag liners as per Tanzania HCWM guidelines.

Awareness on the segregation of waste among healthcare workers was done by supervisors through in-charge of the wards and units in the HCF. Frequent follow up on segregation practices as well as measurement of HCW was done by assigned supervisor in each pilot HCF. All safety precautions including Infection Prevention and Control (IPC) were followed by both healthcare practitioners and investigators (HCW handlers).

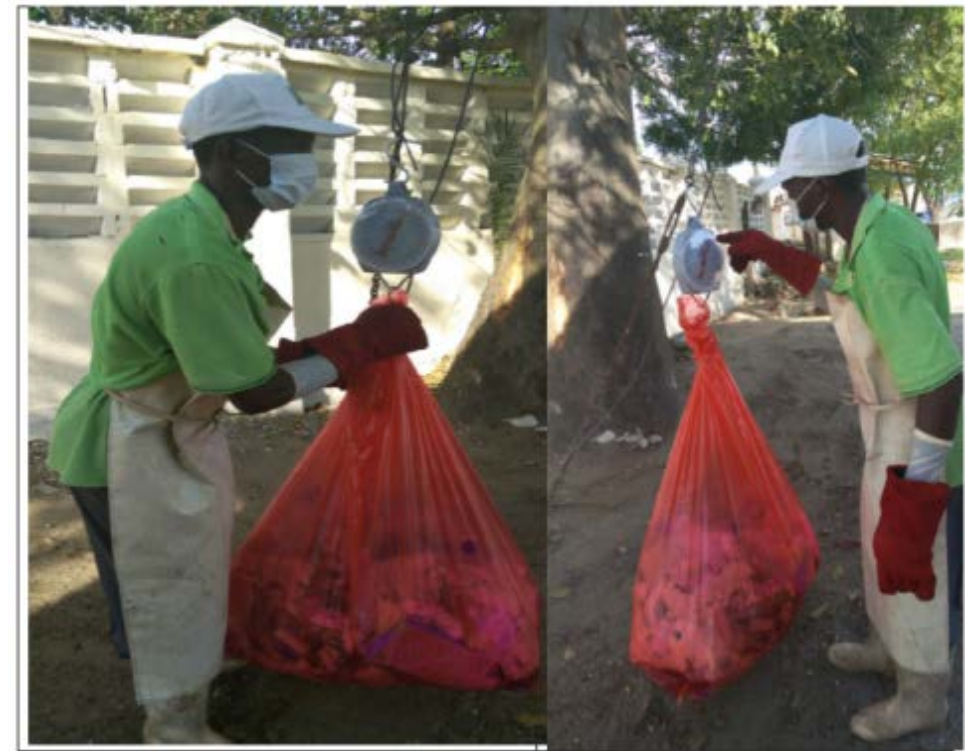

Figure 2. Weighing of healthcare waste. 
Data Analysis: The raw data collected from the field was entered and compiled using SPSS-version 21. The average daily quantity of healthcare waste in the hospitals was computed. The annual waste generation rates were estimated based on the mean daily waste generation multiplying by the number of days in one year (365) assuming the activities related with waste generation are uniform.

Data Quality Management: Training was given to data collectors and supervisors before data collection. Weighing scales were calibrated every morning using a known weight before the actual measurements started. Daily on-site supervision was made by the supervisors during the actual measurements.

Ethical Considerations: Ethical clearance and permission for data collection was obtained from Ministry of health, community development, gender, elderly and children. Verbal and written consent from the head of each health center was also taken prior to data collection.

Data Quality Management: Data collectors and supervisors were trained before data collection exercise. Weighing scales were calibrated every morning using a known weight before the actual measurements started. Daily on-site supervision was made by the supervisors during the actual measurements.

\section{Results and Discussion}

\subsection{Total Medical Waste}

The average general healthcare waste generation rate per health center ranges from $298.9 \mathrm{~kg} /$ day collected at Mwananyamala regional referral hospital to $1554.4 \mathrm{~kg} /$ day collected at Muhimbili national hospital (Figure 3) These values resemble the results reported in Middle East, Latin America and India which ranged between $1.0-3.0 \mathrm{~kg} /$ day [24].

It was revealed that average daily medical general waste generation rate per patient can be arranged in the order $1.87 \mathrm{~kg} /$ person/day (Ilala regional hospital) $>1.56 \mathrm{~kg} /$ person/day $($ Temeke hospital) $>1.42 \mathrm{~kg} /$ person/day (Mwananyamala hospital) $>1.04 \mathrm{~kg} /$ person/day (Muhimbili National Hospital) These values agree with the range of $0.3-1.8 \mathrm{~kg} /$ day established earlier [25].

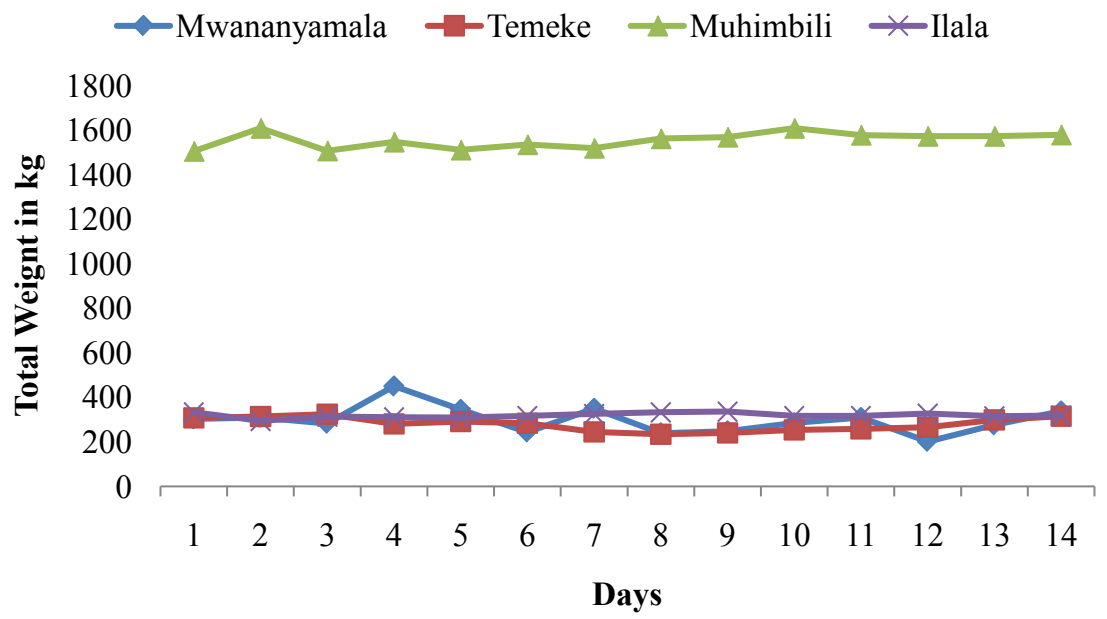

Figure 3. Total weight of medical waste collected per day. 
The high fluctuation in medical waste at Muhimbili National hospital compared to other regional hospitals can be attributed by the large number and type of surgical procedures conducted on that day as well as a large number of in-patients admissions at Muhimbili hospital.

The variation in total of HCW generation among hospitals may be attributed to a variety of reasons such as the type of healthcare establishment, income level and welfare of patients and visitors and diversity of departments [26]. It has been mentioned earlier that it is risky to make comparisons with medical waste records from other countries, due to the variability in the definitions and classifications of medical waste throughout the world [27].

\subsection{Sharps}

The fraction of sharps waste was observed to be $1.65 \%$ in both hospitals to include any device or object used to puncture or lacerate the skin in patient care. This is lower than the one determined earlier 14\% analyzed in two hospitals [28]. According to WHO/UNICEF [29] sharps are used items like syringes and needles, intra-venous (IV) tubing with needles attached, giving sets, scalpel blades, knives, lancets, blades and broken glass, form a class of medical waste known as sharps waste. Sharps waste contains items that can cause cuts or puncture wounds to healthcare workers. Whether sharps are infected or not, are considered highly dangerous and potentially infectious waste, due to their puncture or cutting property [30].

Figure 4 shows the variation of the daily sharps waste incineration rate (in $\mathrm{kg} / \mathrm{day}$ ) recorded. All sharps waste generated are incinerated as the best available option. The overall average sharps waste generation rate was established to range from $8.5 \pm 2.7-13.9 \pm 1.8 \mathrm{~kg} /$ day, with Muhimbili National hospital having the highest and Mwananyamala regional hospital having the lowest.

Higher values of sharps waste generated observed at Muhimbili national referral hospital is not surprising due to emergency cases referred to $\mathrm{MNH}$ from Temeke, Amana, Mwananyamala and private hospitals located within the city

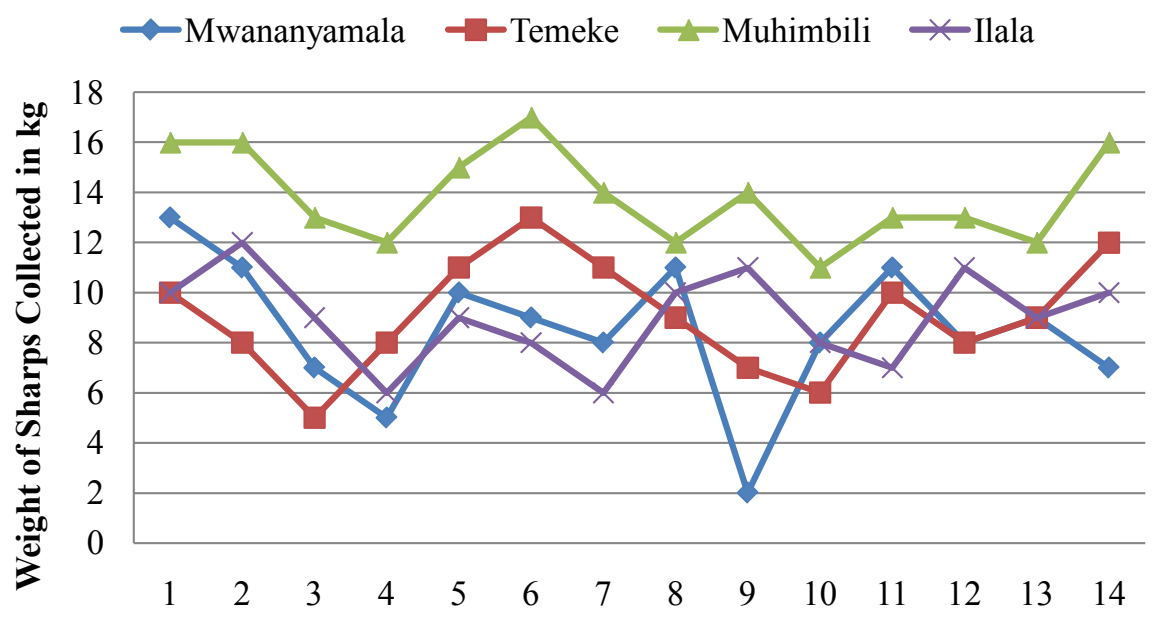

Figure 4. Variation of sharps collected in kg/day. 
and from the surrounding districts and other regions of the country. The observed values are lower than the average sharps waste generation rate observed earlier [31], which was established to be $40.8 \mathrm{~kg} /$ day with wider daily variations between 10 and $90 \mathrm{~kg}$ sharps waste per day. These values are higher than those detected in Ethiopia, where the rate of sharp generation in 10 different hospitals was $0.267 \pm 0.107 \mathrm{~kg} /$ day [32].

\section{Infectious Waste}

Waste which was measured was those items contaminated with blood or other body fluids. Cultures and stocks of infectious agents from laboratory work [31]. Waste from infected patients in isolation wards. Waste contaminated with blood or other body fluids include free-flowing blood, waste pharmaceutical materials (expired chemicals) blood components and other body fluids; dressings, bandages, swabs, gloves, masks, gowns, drapes and other material contaminated with blood or other body fluids; and waste that has been in contact with the blood of patients undergoing haemodialysis (e.g. disposable towels, gowns, aprons, gloves and laboratory coats). Figure 5 shows the quantity of infectious waste collected from different hospitals.

The study analyzed, infectious waste excluding the plastic bottles and pathological waste, occupy about $34.1 \%$ of the entire waste materials. Muhimbili hospital has the highest average of $537.8 \pm 21.2 \mathrm{~kg} /$ day followed by Ilala hospital with $124.4 \pm 4.8 \mathrm{~kg} /$ day, Temeke hospital $90.1 \pm 10.9 \mathrm{~kg} /$ day and the lowest detected at Mwananyamala hospital with $84.1 \pm 29.0 \mathrm{~kg} /$ day. These values are in line with other studies conducted in Lebanon [33], which ranges between 188 $\mathrm{kg} /$ day $-490 \mathrm{~kg} /$ day. In Tanzania it corresponds to results obtained earlier from Amana Hospital recorded $649 \mathrm{~kg} /$ day [27].

Thus, for the first time in Tanzania, this study has provided information on the infectious waste generation excluding the plastic bottles and pathological items, allowing bench-marking between hospitals. The calculated generation rates can serve as a reference for hospitals and controlling authorities. Indeed, in case the generation rate of a hospital is far from the average rate of the category

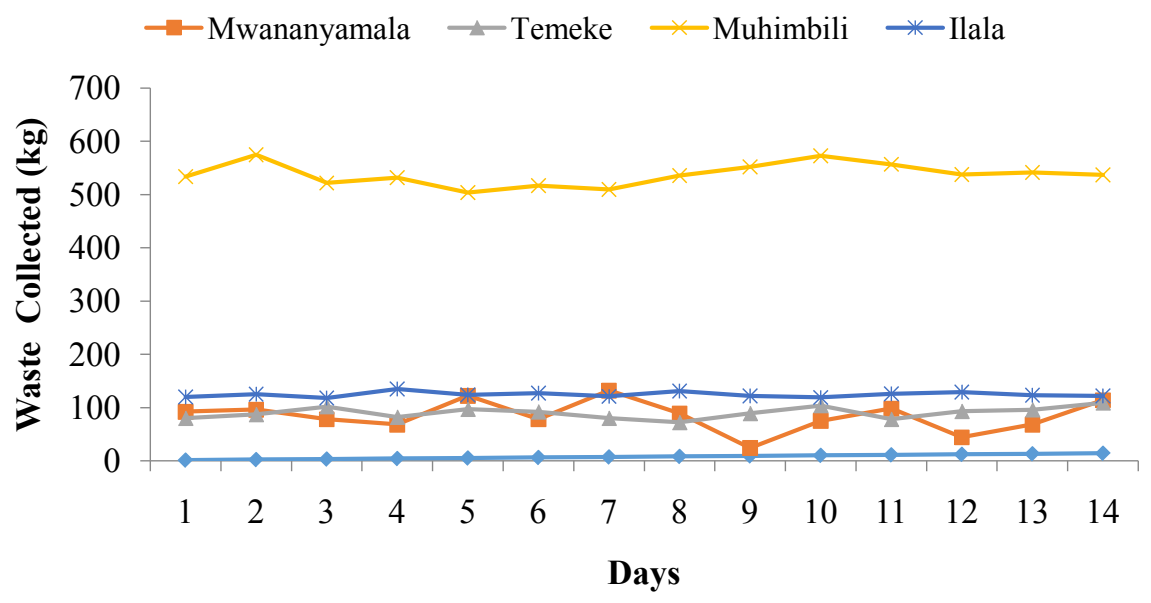

Figure 5. The quantity of infectious waste collected from different hospitals. 
it belongs to, this could be an alerting sign on its sorting and waste management practices, whether for the hospital's administrations or the local authorities.

\section{Pathological Waste}

Pathological waste is a subcategory of bio-hazardous waste, which originates from surgical procedures or research that involves removal of organs, tissues or body parts like waste from operation theaters will also contain removed body organs (like tonsils, appendices, limbs etc.) which renders the medical waste scary, and nuisance. Figure 6 shows the pathological amount collected in hospitals.

Pathological waste occupies about $8.6 \%$ of the total hospital waste collected. Muhimbili hospital register the highest with average of $116.1 \mathrm{~kg} /$ day followed by $35.5 \mathrm{~kg} /$ day recorded at Mwananyamala hospital, $30.2 \mathrm{~kg} / \mathrm{day}$ Ilala hospital and the lowest is 28.9 recorded at Temeke hospital. These correspond to values detected earlier [24], who detected $24.6 \mathrm{~kg} /$ day of pathological waste.

The amount measured for pathological waste call upon the use biogas technology. This will lead to production of methane by anaerobic digestion helps to reduce the amount of waste that must be disposed of using other methods like incineration or land filling that generally does not have environmental benefits.

\section{Non-Infectious Waste}

When we consider the rate of generation of non-infectious waste the order can be arranged as $0.56 \mathrm{~kg} / \mathrm{bed} \cdot d a y$ (Muhimbili National Hospital) $<0.58 \mathrm{~kg} / \mathrm{bed} \cdot$ day (Ilala Hospital) $<0.61 \mathrm{~kg} /$ bed.day (Mwananyamala Hospital) $<0.68 \mathrm{~kg} /$ bed.day (Temeke Hospital) These values are extremely lower than the one determined earlier in Amana and Ligula hospital waste generation [27].

The non-infectious waste as indicated under (Figure 7) are mostly generated from the administrative and housekeeping activities of healthcare facility establishments which include waste generated during maintenance of health-care premises or from food preparation and facility surrounding such as Packaging, food remains, scraps, paper, unwanted flowers, empty saline bottles, non-bloody

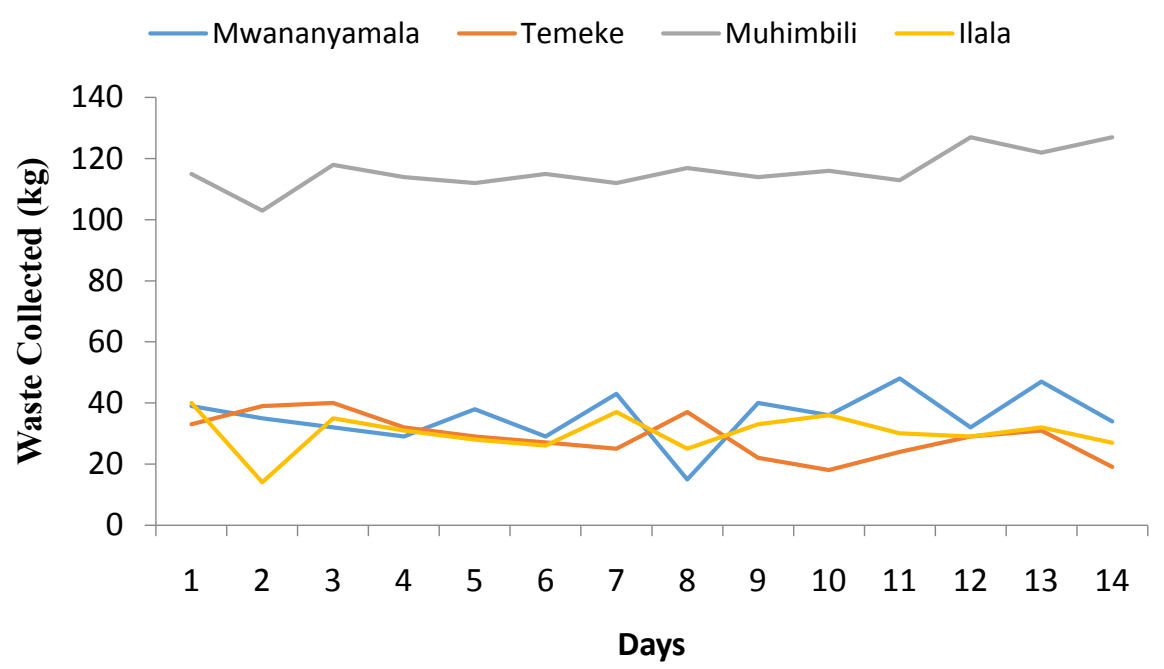

Figure 6. Amount of pathological waste. 


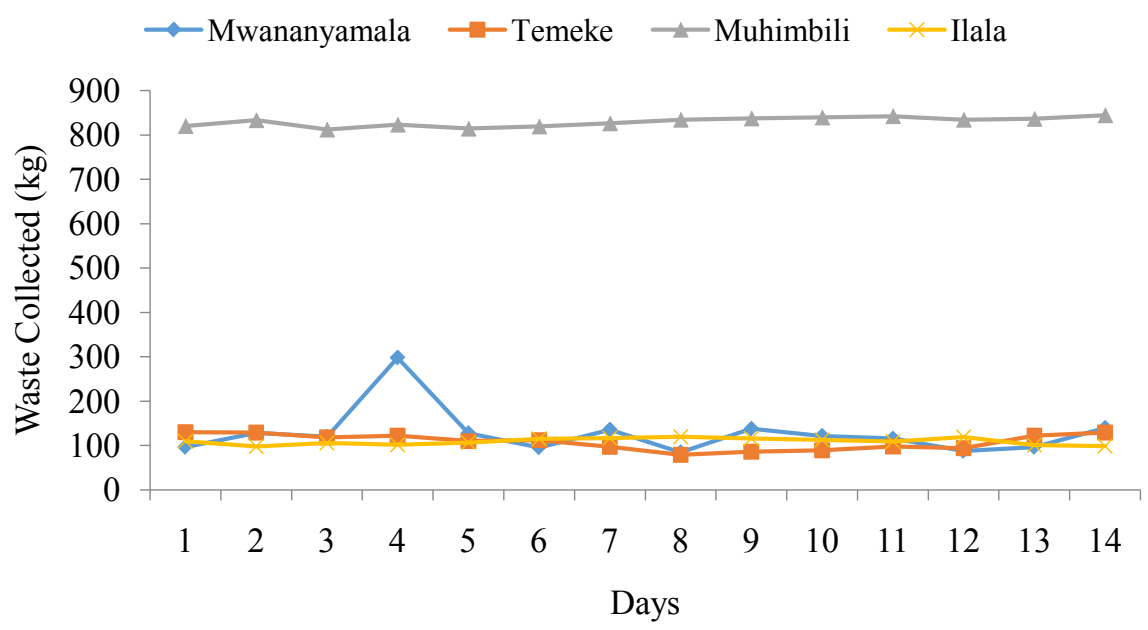

Figure 7. Non-infectious waste samples measured from different hospitals.

diapers; non-bloody IV tubing and bags, uncontaminated gowns, gloves, masks, hats and shoe covers, plastic containers, newspapers, magazines, paper, packaging materials for drugs or medicine, food remains plastic water bottles (as described in non-infectious plastics), worn-out clothes, cans, fruits remains etc.

The average ranges from $98.00 \pm 7.50 \mathrm{~kg} /$ day (Ilala Hospital) to $833.00 \pm 10.41$ $\mathrm{kg} /$ day (Muhimbili National Hospital). These values are in line with the value determined earlier in Dar es Salaam city of average of $739 \mathrm{~kg} /$ day [27].

There are several factors to consider when determining the rate of production of general waste in hospitals. One of the factors is the number of beds in hospitals. As the number of beds increases the waste generation per bed becomes high. Another factor is standard of living of people using the respective hospital [25]. As the standard of living becomes low the rate of production of non-infections waste increases.

The analysis also showed generation rate for general waste to be higher compare to other categories of waste such as pathological. This is good news to hospital administrators, as if well segregated, can easily and economically be collected, treated and disposed of using the normal municipal technologies to reduce cost and help hospitals to concentrate with much hazardous waste which are dangerous and costly to handle. The rate of medical waste collection in both hospitals is not very good as some of wastes are left uncollected which call for more effort to be kept in this area as medical waste left uncollected can harm human health and environment.

\section{Plastics Non-Infectious and Infectious Plastic Waste}

Plastics are integral part of society and have varied application. Plastics are composed of a network of molecular monomers bound together to form macromolecules. According to another study [34], there are increasing concerns due to non-degradability and generation of toxic gases on combustion during incineration.

Plastic refers to wide range of synthetic or semi-synthetic organic polymeric materials of high molecular weight. They are usually synthetic hence non-degradable 
and most commonly they are derived from petrochemicals but many cases are partially natural [35]. A polymer may contain other additives like plasticizers, stabilizers, lubricant, UV absorbing material, flame retardants to improve performance. Plastics have permeated every facet of human life such as packaging, agriculture, water transportation, building construction, telecommunication, education, medicine, transportation, defense, consumer durables to name a few. Figure 8, shows levels of non-hazardous plastic materials.

Usually in a hospital setup non plastic waste are mixed with other non-infectious materials. But for the purpose of this study a separate waste bin/container colored green was placed in all waste generation point to collect all plastics materials generated in that particular day. A close supervision was conducted to ensure segregation of waste is done correctly especially for and then at the end of the day weighed and recorded. The noninfectious plastic wastes occupy about $3.6 \%$ of the total waste collected. Ilala hospital records the highest value with average of $23.4 \mathrm{~kg} /$ day, followed by Temeke Hospital with average of $22.7 \mathrm{~kg} /$ day, Mwananyamala hospital $21.9 \mathrm{~kg} /$ day and the smallest was detected at Muhimbili hospital $21.7 \mathrm{~kg} /$ day.

The development of intravenous (IV) bags and tubing from plastics led to other disposable ubiquitous to healthcare centers. These are frequently used in hospitals for drug-delivery, treat of dehydrated patients through fluid replacement, blood transfuse, and to correct electrolyte imbalances. These IV bags and tubing in hospitals constitute $20 \%-25 \%$ of hospital waste.

Figure 9 shows the quantity of infectious plastic materials collected in hospitals. For these infectious materials it occupies $4.1 \%$ of the entire waste material collected where Muhimbili recorded the highest volume $36.5 \pm 3.9 \mathrm{~kg} / \mathrm{day}$ followed by $22.2 \pm 3.6$ at Ilala hospital, $21.3 \pm 4.2 \mathrm{~kg} /$ day Temeke Hospital and the lowest is at Ilala hospital $21.0 \pm 4.6 \mathrm{~kg} /$ day.

The technology employed is mechanical recycling is based on traditionally

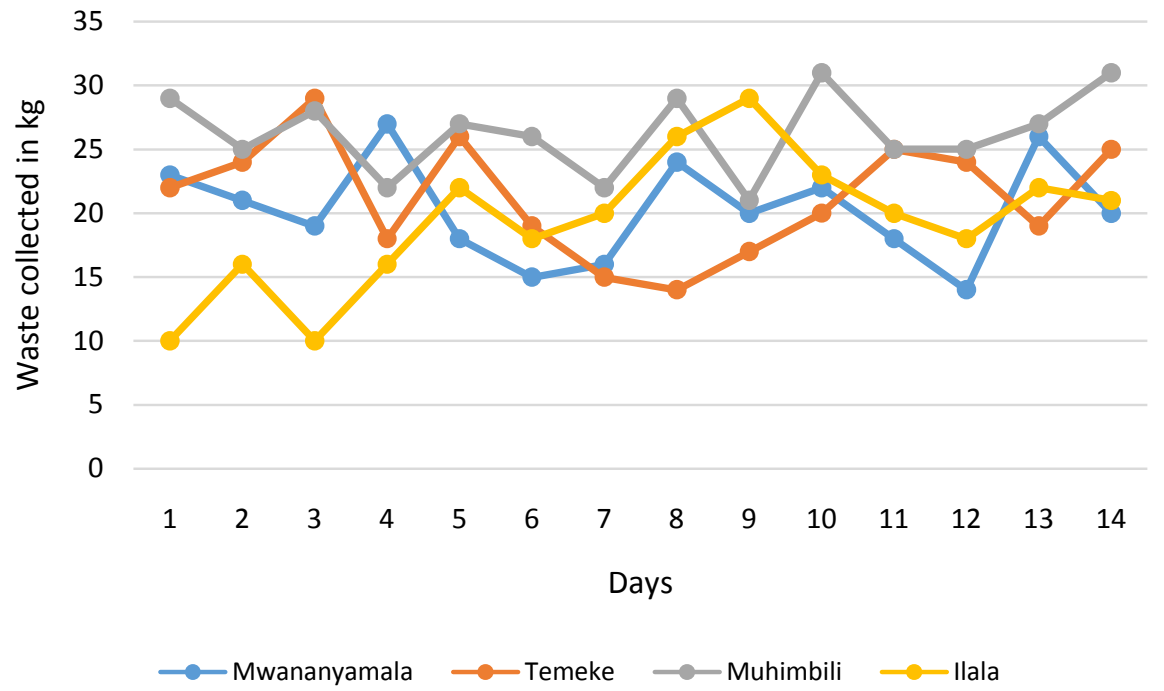

Figure 8. Quantity of non infectious plastics from different hospitals. 


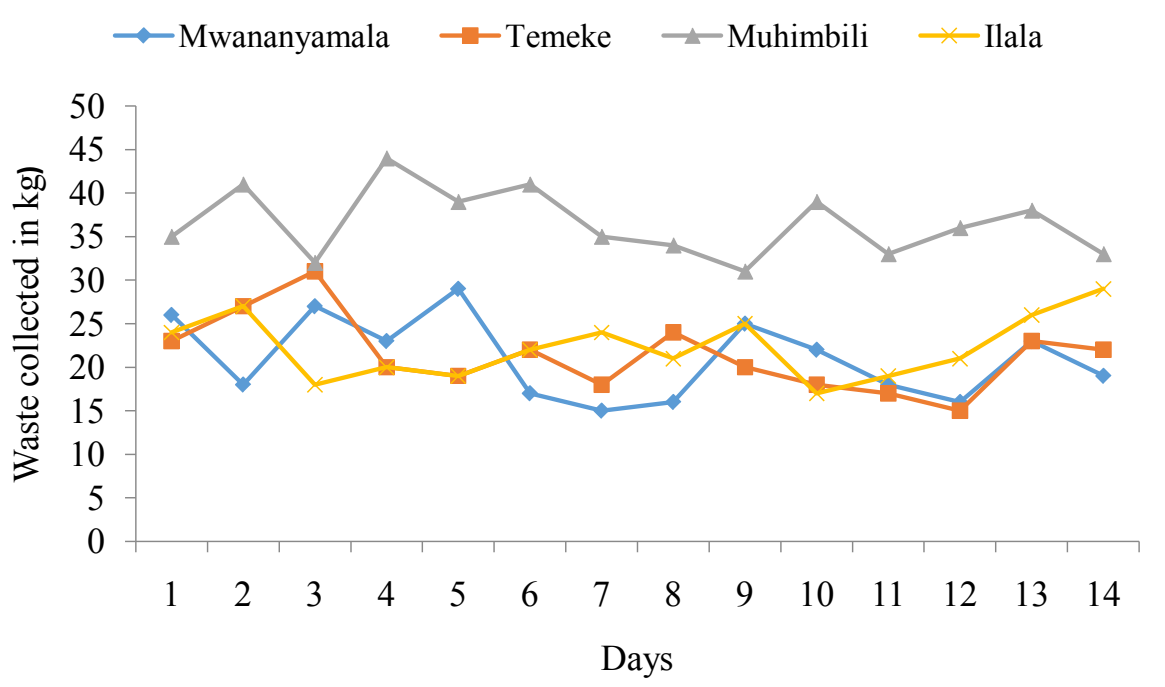

Figure 9. Quantity of infectious plastic materials collected in hospitals.

grinding extrusion to obtain granules. Mechanical recycling is the most preferred and widely used method of recycling and it recycles particular type of polymers used in water and soft drink bottles [36]. The use of plastic waste as alternative fuel will help to reduce the energy cost along with reduction in the $\mathrm{CO}_{2}$ emissions [37]. During co-incineration of plastic waste in blast furnace and cement kilns, it is completely burnt at high temperature and slag which remain as waste, can be further utilized as cement and road construction [34]. However, the emission of toxic gases and heavy metals during incineration it turns down the possibility of incineration as good environmentally friendly technique [38].

\section{Estimation of Healthcare Waste Production in a Year}

Accurate information on the quantity and the characteristics of medical waste is necessary to assist in the determination of suitable and appropriate disposal methods [39].

As a result of this practice there is a wide variation of reported medical waste generation rates [40]. In order to more accurately estimate medical waste generation rates with more robust and reliable figures, the total yearly collected number of medical waste in different categories from different hospitals and healthcare institutions were obtained and used in this study. Table 1 shows the estimate of different categories of healthcare waste collected in a year. For convenient 366 days was used to estimate the values presented in tones.

Apart from total waste which records the highest value about 897.9 tonnes, infectious waste followed with about 306.1 tonnes. The value is less high than the values detected earlier 0.098 tonnes [33]. Total sharps are 14.8 tonnes/year which are around 151 times higher than those detected earlier, which they record 0.098 tonnes/year [33].

Since these figures predict continued increasing trends, further studies are necessary to assess the estimated results with the real future waste generation through computerized worked formulars per levels and categories of healthcare facilities. In order to reduce the healthcare waste management load and cost, the 
Table 1. Estimated healthcare waste categories per year (tonnes).

\begin{tabular}{ccccc}
\hline Category of Waste & Mwananyamala & Temeke & Muhimbili & Ilala \\
\hline Total waste & 113.30 & 145.16 & 1062.15 & 120.38 \\
Sharps & 2.92 & 3.74 & 27.38 & 3.10 \\
Infectious & 23.36 & 29.93 & 219 & 24.82 \\
Pathological & 14.02 & 17.96 & 131.40 & 14.89 \\
Non-infectious & 55.48 & 71.08 & 520.13 & 58.95 \\
Non Infectious Plastic & 5.84 & 7.48 & 54.75 & 6.21 \\
Infectious Plastic & 11.68 & 14.97 & 109.50 & 12.41 \\
\hline
\end{tabular}

mixing of non-infectious waste with infectious waste materials must be prevented through best practices at hospital setting. The best way to control the impact of medical waste is to produce less of it, and one of the most effective ways to do this is to ensure that only infectious and pathogenic medical waste is sent for treatment, other hospital waste should be treated in the same manner as municipal household waste.

\section{Conclusions and Recommendations}

The analysis shows generation rate for non-infectious waste to be higher compared to other categories of waste such as pathological, sharps and infectious waste. This variation in waste generation among hospitals may be attributed to a variety of reasons such as hospital specialization, proportion of disposable items used in healthcare activities and the practices as well as the efficiency of the segregation of medical wastes.

Understanding waste generation rate at different levels of healthcare facilities is key to facilitate easy planning and budgeting and resource mobilization for effective improved healthcare waste management.

The results switch alarm to hospital administrators, environmental management experts, healthcare workers, Ministry of Health, Community Development, Gender, Elderly and Children, Ministry of Local Government, and Non-Governmental Organizations working in related fields and all other stakeholders to give special attention and priority in setting a related share in their budgets for proper management of medical waste in their health facilities. Further to that much effort need to be exerted on waste segregation practices, treatment and safe disposal to reduce cost of disposal and also ensure safety of the public health and the living environment.

\section{Acknowledgements}

The authors wish to express their gratitude appreciation to Ministry of Health, Community Development, Gender, Elderly and Children for the financial support. Also the completion of this study has been the results of assistance received from all management teams of the hospitals involved in the study (Temeke, 
Mwananyamala and Ilala Regional referral hospitals and Muhimbili National Hospital).

\section{Conflicts of Interest}

The authors declare no conflicts of interest regarding the publication of this paper.

\section{References}

[1] WHO (2020) Infection Prevention and Control for the Safe Management of a Dead Body in the Context of COVID-19. Geneva.

https://apps.who.int/iris/bitstream/handle/10665/331538/WHO-COVID-19-1PC_D BMgmt-2020.1-eng.pdf

[2] WHO (2020) Water, Sanitation, Hygiene, and Waste Management for the COVID-19 Virus, Interim Guidance. World Health Organization, Geneva. https://apps.who.int/iris/handle/10665/331846

[3] Osterholm, M.T., Moore, K.A. and Gostin, L.O. (2015) Public Health in the Age of Ebola in West Africa. JAMA Internal Medicine, 175, 7-8.

https://doi.org/10.1001/jamainternmed.2014.6235

[4] Bausch, D.G., Towner, J.S., Dowell, S.F., Kaducu, F., Lukwiya, M., Sanchez, A., et al. (2007) Assessment of the Risk of Ebola Virus Transmission from Bodily Fluids and Fomites. The Journal of Infectious Diseases, 196, S142-S147. https://doi.org/10.1086/520545

[5] Richard, V.S., Kenneth, J., Ramaprabha, P., Kirupakaran, H. and Chandy, G.M. (2001) Impact of Introduction of Sharps Containers and of Education Programmes on the Pattern of Needle Stick Injuries in a Tertiary Care Centre in India. Journal of Hospital Infection, 47, 163-165. https://doi.org/10.1053/jhin.2000.0865

[6] Kerley, F.R. and Nissly, B.E. (1992) Total Quality Management and Statistical Quality Control: Practical Applications to Waste Stream Management. Hospital Materiel Management Quarterly, 14, 40-59. https://pubmed.ncbi.nlm.nih.gov/10121996/

[7] Ananth, A.P., Prashanthini, V. and Visvanathan, C. (2009) Healthcare Waste Management in Asia. Waste Management, 30, 154-161.

https://doi.org/10.1016/j.wasman.2009.07.018

[8] Doylo, T., Alemayehu, T. and Baraki, N. (2019) Knowledge and Practice of Health Workers about Healthcare Waste Management in Public Health Facilities in Eastern Ethiopia. Journal of Community Health, 44, 284-291. https://doi.org/10.1007/s10900-018-0584-z

[9] Gitonga, L.K. (2017) Factors Influencing Waste Segregation among Staff in Chuka Level Four Hospital. Rehabilitation Science, 2, 91-100.

[10] Kuroiwa, C., Suzuki, A., Yamaji, Y. and Miyoshi, M. (2004) Hidden Reality on the Introduction of Auto-Disable Syringes in Developing Countries. Southeast Asian Journal of Tropical Medicine and Public Health, 35, 1019-1023. https://pubmed.ncbi.nlm.nih.gov/15916108/

[11] WHO (1999) Unsafe Injection Practices and Transmission of Blood Borne Pathogens. Bulletin of the World Health Organization, 77, 787-819.

https://pubmed.ncbi.nlm.nih.gov/10593026/

[12] WHO (2015) Burning Ebola Waste Safely. Geneva http://www.who.int/features /2015/ebola-ppe-disposal/en/ 
[13] Lowe, J.J., Gibbs, S.G., Schwedhelm, S.S., Nguyen, J. and Smith, P.W. (2014) Nebraska Bio-Containment Unit Perspective on Disposal of Ebola Medical Waste. American Journal of Infection Control, 42, 1256-1257. https://doi.org/10.1016/j.ajic.2014.10.006

[14] WHO (2014) Preparation of National Health-Care Waste Management Plans in Sub-Saharan Countries, Guidance Manual. World Health Organization, Geneva. https://apps.who.int/ iris/handle/10665/43118

[15] Matiko, D. (2011) Managing Disposal of Unwanted Pharmaceuticals at Health Facilities in Tanzania: A Case of Dar es Salaam Region Public Health Facilities. MSc. Pharmaceutical Management Dissertation, Muhimbili University of Health and Allied Sciences, Dar es Salaam, 40-41.

[16] Tadesse, M.L. and Kumie, A. (2014) Healthcare Waste Generation and Management Practice in Government Hospitals of Addis Ababa, Ethiopia. BMC Public Health, 14, Article No.: 1221. https://doi.org/10.1186/1471-2458-14-1221

[17] Caniato, M., Tudor, T. and Vaccari, M. (2015) International Governance Structures for Healthcare Waste Management: A Systematic Review of Scientific Literature. Journal of Environmental Management, 153, 93-107. https://doi.org/10.1016/j.jenvman.2015.01.039

[18] Tsakona, M., Anagnostopoulou, E. and Gidarakos, E. (2007) Hospital Waste Management and Toxicity Evaluation: A Case Study. Waste Management, 27, 912-920. https://doi.org/10.1016/j.wasman.2006.04.019

[19] De Titto, E., Savino, A.A. and Townend, W.K. (2012) Healthcare Waste Management: The Current Issues in Developing Countries. Waste Management \& Research, 30, 559-561. https://doi.org/10.1177/0734242X12447999

[20] URT (2018) National Strategic Plan for Healthcare Waste Management (2018-2022) Ministry of Health, Community Development, Gender, Elderly and Children, Dodoma.

http://documents1.worldbank.org/curated/en/569561523412087039/text/TanzaniaNational-HCWM-Plan-2018.txt

[21] Ogola, J.S., Chimuka, L. and Tshivhase, S. (2011) Management of Municipal Solid Wastes: A Case Study in Limpopo Province, South Africa. In: Kumar, S., Ed., Integrated Waste Management, In Tech, Rijeka, 8-19.

https://www.intechopen.com/books/integrated-waste-management-volume-i/mana gement-of-municipal-solid-wastes-a-case-study-in-limpopo-province-south-africa

[22] Olaniyi, F.C., Ogola, J.S. and Tshitangano, T.G. (2019) Efficiency of Health Care Risk Waste Management in Rural Healthcare Facilities of South Africa: An Assessment of Selected Facilities in Vhembe District, Limpopo Province. International Journal of Environmental Research and Public Health, 16, 1-19. https://doi.org/10.3390/ijerph16122199

[23] World Bank (2016) The Road Less Traveled Unleashing Public Private Partnerships in Tanzania (8th Tanzania Economic Update). World Bank, Dar es Salaam. https://www.worldbank.org/en/country/tanzania/publication/tanzania-economic-u pdate-the-road-less-traveled-unleashing-public-private-partnerships-in-tanzania

[24] Hamoda, H.M., El-Tomi, H.N. and Bahman, Q.Y. (2005) Variations in Hospital Waste Quantities and Generation Rates. Journal of Environmental Science and Health, Part A: Toxic/ Hazardous Substances and Environmental Engineering, 40, 467-476. https://doi.org/10.1081/ESE-200045650

[25] Mato, R.R. and Kassenga, G.R. (1997) Problems of Management of Medical Solid Wastes in Dar es Salaam and their Remedial Measures. Resources, Conservation 
and Recycling, 21, 1-16. https://doi.org/10.1016/S0921-3449(97)00010-4

[26] Komilis, D., Fouki, A. and Papadopoulos, D. (2012) Hazardous Medical Waste Generation Rates of Different Categories of Health-care Facilities. Waste Management, 32, 1434-1441. https://doi.org/10.1016/j.wasman.2012.02.015

[27] Kagonji, I.S. and Manyele, S.V. (2011) Analysis of the Measured Medical Waste Generation rate in Tanzanian District Hospitals Using Statistical Methods. African Journal of Environmental Science and Technology, 5, 815-833. https://www.ajol.info/index. php/ajest/article/view/72088

[28] WHO, (2015b) Burning Ebola Waste Safely. Geneva. http://www.who.int/features/2015/ebola-ppe-disposal/en/

[29] WHO/UNICEF (2015) Water, Sanitation and Hygiene in Healthcare Facilities: Status in Low and Middle Income Countries. World Health Organization, Geneva. https://www.who.int/water_sanitation_health/publications/wash-hcf-10things.pdf

[30] Matee, V.E. and Manyele, S.V. (2016) Assessment of Sharps Waste Management Practices in a Referral Hospital. African Journal of Environmental Science and Technology, 10, 86-95. https://doi.org/10.5897/AJEST2015.1939

[31] Meleko, A., Tesfaye, T. and Henok, A. (2018) Assessment of Healthcare Waste Generation Rate and Its Management System in Hospitals of Bench Maji Zone. Ethiopian Journal of Health Sciences, 28, 125-134. https://doi.org/10.4314/ejhs.v28i2.4

[32] Maamari, O., Brandam, C., Lteif, R. and Salameh, D. (2015) Healthcare Waste Generation Rates and Patterns: The Case of Lebanon. Waste Management, 43, 550-554. https://doi.org/10.1016/j.wasman.2015.05.005

[33] Meleko, A. and Adane, A. (2018) Assessment of Health Care Waste Generation Rate and Evaluation of its Management System in Mizan Tepi University Teaching Hospital (MTUTH) Bench Maji Zone, South West Ethiopia. Ann Rev Resear, 1, 75-83.

[34] Singh, P. and Sharma, V.P. (2016) Integrated Plastic Waste Management: Environmental and Improved Health Approaches. Procedia Environmental Sciences, 35, 692-700. https://doi.org/10.1016/j.proenv.2016.07.068

[35] Eerkes-Medrano, D., Thompson, R.C. and Aldridge, D.C. (2015) Microplastics in Freshwater Systems: A Review of the Emerging Threats, Identification of Knowledge Gaps and Prioritization of Research Needs. Water Research, 75, 63-82. https://doi.org/10.1016/j.watres.2015.02.012

[36] Benjamin, S., Pradeep, S., Josh, M.S., Kumar, S. and Masai, E. (2015) Monograph on the Remediation of Hazardous Phthalates. Journal of Hazardous Materials, 298, 58-72. https://doi.org/10.1016/j.jhazmat.2015.05.004

[37] Lee, B.-K., Ellenbcker, M.J. and Moure-Eraso, R. (2002) Analyses of the Recycling Potential of Medical Plastic Wastes. Waste Management, 22, 461-470. https://doi.org/10.1016/S0956-053X(02)00006-5

[38] Windfeld, E.S. and Brooks, M.S.-L. (2015) Medical Waste Management: A Review. Journal of Environmental Management, 163, 98-108. https://doi.org/10.1016/j.jenvman.2015.08.013

[39] Uysal, F. and Tinmaz, E. (2004) Medical Waste Management in Trachea Region of Turkey: Suggested Remedial Action. Waste Management \& Research, 22, 403-407. https://journals.sagepub.com/doi/10.1177/0734242X04045690 https://doi.org/10.1177/0734242X04045690

[40] WHO (2004) Safe Management of Wastes from Healthcare Activities. 2nd Edition, 
World Health Organization, Geneva.

https://www.who.int/water_sanitation_health/publications/safe-management-of-wa stes-from-healthcare-activities/en/ 